\title{
Efeito de agentes químicos na conservação pós-colheita de inflorescências de Alpinia purpurata (Vieill) K. Schum ${ }^{1}$
}

\author{
CLAUDIA FABRINO MACHADO MATTIUZ², BEN-HUR MATTIUZ ${ }^{3}$, TERESINHA DE JESUS DELÉO RODRIGUES ${ }^{3}$, \\ JOSÉ FERNANDO DURIGAN ${ }^{3}$ e KATHIA FERNANDES LOPES PIVETTA ${ }^{4}$
}

\begin{abstract}
RESUMO
Alpinia purpurata é uma flor tropical atualmente muito utilizada como flor de corte devido à beleza e durabilidade de suas inflorescências. O experimento foi realizado para verificar o efeito de diferentes compostos químicos, inibidores da ação do etileno e de bactericidas na conservação pós-colheita das inflorescências de alpínia. $\mathrm{O}$ experimento foi conduzido em delineamento inteiramente casualizado, em esquema fatorial, com cinco tratamentos e quatro repetições, com três inflorescências cada uma. Os tratamentos utilizaram água destilada, 500 ppb e 1000 ppb de 1-metilciclopropeno (1-MCP), 0,35 $\mathrm{mL} . \mathrm{L}^{-1}$ de amônia quaternária, $1 \mathrm{mM}$ de tiossulfato de prata (STS). Foram avaliados os aspectos qualitativos: cor, turgescência, escurecimento e curvatura das inflorescências. $\mathrm{O}$ tratamento com 1-MCP revelou-se o mais promissor para a preservação da qualidade das inflorescências durante os doze dias de vida de vaso. As alpínias foram muito sensíveis ao STS (1mM) e perderam a qualidade aos dois dias de vida no vaso.
\end{abstract}

Palavras-chave: alpínia, 1-metilciclopropeno, pulsing, amônia quaternária, tiossulfato de prata.

\section{ABSTRACT \\ Effect of chemicals agents on postharvest conservation of Alpinia purpurata (Vieill) K. Schum inflorescences}

Alpinia purpurata is a tropical flower largely used as cut flower due to the beauty and durability of the inflorescences. The experiment was conducted to verify the effects of inhibitors of ethylene and bactericides, on conservation of red ginger cut flowers. The following treatments were used: 1) distilled water, 2) $500 \mathrm{ppb}$ 1-methylcyclopropene (1-MCP), 3) 1000 ppb 1-MCP, 4) $0,35 \mathrm{~mL} \cdot \mathrm{L}^{-1}$ quaternary ammonium, 5) $1 \mathrm{mM}$ silver thiosulphate. The qualitative aspects: color, turgor, browning and inflorescences curvature were evaluated. The 1-MCP treatment was the most promising for preservation of red ginger cut inflorescences during 12 days of vase-life. Red gingers inflorescences were very sensitive to STS $(1 \mathrm{mM})$ and lost quality after two days of vase-life.

Key-words: red ginger, 1-methylcyclopropene, pulsing, quaternary ammonium, silver thiosulfate.

\section{INTRODUÇÃO}

Alpinia purpurata é uma planta tropical herbácea da família Zingiberaceae, conhecida por alpínia vermelha ou gengibre vermelho, cuja inflorescência é formada por brácteas dispostas em espiral assemelhando-se a uma espiga (KEPLER \& MAU, 1996). A inflorescência de alpínia é composta por várias unidades morfológicas distintas como pétalas, sépalas, androceu, gineceu, brácteas e raque (DAHLGREN et al., 1985) e, possivelmente, a interação entre esses órgãos pode ter algum efeito sobre a longevidade floral. Desse modo, os sintomas de senescência e seu desenvolvimento podem ser diferentes daqueles que ocorrem em flores verdadeiras como rosas e cravos.

\footnotetext{
${ }^{1}$ Parte da Tese de Doutorado apresentada pelo primeiro autor à Faculdade de Ciências Agrárias e Veterinárias (FCAV-UNESP), Campus de Jaboticabal.

2 Professora, Doutora do Curso de Agronomia do Centro Universitário Moura Lacerda. Av. Dr. Oscar de Moura Lacerda, 1520 , 14076-510 Ribeirão Preto (SP).

${ }^{3}$ Prof. Dr. do Curso de Agronomia da FCAV-UNESP, Campus de Jaboticabal. Via de acesso Prof. Paulo Donato Castellane, s/n. 14884-900 Jaboticabal (SP).

${ }^{4}$ Professora, Doutora do Curso de Agronomia da FCAV-UNESP.
} 
Em muitos casos, a longevidade das flores é determinada pelas pétalas (MAYAK \& HALEVY, 1980), no entanto, outros órgãos florais, como folhas e brácteas, podem determinar o período de vida de vaso, como em inflorescências de Protea repens, cuja rápida descoloração e escurecimento das brácteas é a principal causa da curta vida pós-colheita (AKAMINE et al., 1979). Em inflorescências de Alpinia purpurata, o murchamento e o escurecimento das brácteas estão associados à redução da qualidade pós-colheita, e foram atribuídos, respectivamente, ao bloqueio vascular dos tecidos e à redução de substâncias de reserva (PAULL, 1991).

A perda da qualidade das flores cortadas está relacionada a vários processos fisiológicos (HALEVY \& MAYAK, 1974), com possíveis interações entre os diversos componentes florais (HALEVY, 1985) e, também, pode estar diretamente relacionada a fatores qualitativos, como, por exemplo, alterações na estabilidade da cor durante a vida de vaso (BOROCHOV et al., 1976).

Os efeitos do etileno na senescência de flores têm sido relatados por vários autores (BURG, 1962; HALEVY \& MAYAK, 1981; WOODSON et al., 1992; NADEAU et al., 1993), sendo alguns compostos químicos usados para inibir os efeitos do etileno, como o tiossulfato de prata (STS) (CAMERON \& REID, 1983), norbornadieno (WANG \& WOODSON, 1989) e o 1-metilciclopropeno (1-MCP) (SEREK et al., 1994b; SEREK et al., 1994c; SEREK et al., 1995). O 1-metilciclopropeno (1-MCP) é um composto volátil não tóxico, recentemente descoberto, e que tem demonstrado ser um eficiente inibidor da ação do etileno em frutas, hortaliças e flores (SEREK et al., 1995).

As soluções com ação microbiana têm sido utilizadas para inibir o crescimento de microrganismos associados à senescência de flores cortadas. Os compostos de amônia quaternária possuem efeito bactericida, e são considerados menos tóxicos e mais estáveis do que o citrato e o sulfato de 8-hidroxiquinolina (FARNHAM et al., 1978; LEVY \& HANAN 1978; HALEVY \& MAYAK, 1981).

O presente trabalho objetivou avaliar o efeito de alguns compostos químicos inibidores da ação do etileno e de bactericidas, na manutenção das características qualitativas de inflorescências de Alpinia purpurata.

\section{MATERIAL E MÉTODOS}

Inflorescências de Alpinia purpurata foram colhidas no ponto de colheita comercial (CRILEY \& PAULL, 1993) e transportadas por dez horas, na posição vertical, com a base das hastes imersas em água, do Estado do Rio de Janeiro até o laboratório de Fisiologia Vegetal, do
Departamento de Biologia Aplicada à Agropecuária da FCAV-UNESP, em Jaboticabal (SP). No laboratório, as hastes florais foram padronizadas em $40 \mathrm{~cm}$ de comprimento, fazendo-se o corte na base dentro de recipientes com água destilada. Após a padronização, as flores foram pesadas e submetidas aos tratamentos: 1) água destilada (AD); 2) 1-metilciclopropeno (1-MCP) a 500 ppb; 3) 1metilciclopropeno a 1000 ppb; 4) amônia quaternária a $\left.0,35 \mathrm{~mL} . \mathrm{L}^{-1} ; 5\right)$ tiossulfato de prata (STS) a $1 \mathrm{mM}$.

$\mathrm{O}$ experimento foi conduzido em delineamento inteiramente casualizado, segundo esquema fatorial composto por dois fatores: cinco tratamentos, e sete datas de avaliação $(0 ; 2 ; 4 ; 6 ; 8 ; 10 ; 12$ dias). Foram utilizadas quatro repetições por tratamento, com três inflorescências cada repetição, totalizando 60 inflorescências.

Para a aplicação dos tratamentos com 1-MCP, as inflorescências foram tratadas com o produto EthylBloc $\square$, na formulação pó molhável, contendo $0,14 \%$ de ingrediente ativo. A aplicação constou da colocação das inflorescências em frascos com água destilada, dentro de câmara hermética e exposição ao produto, nas concentrações mencionadas, por seis horas, a $22 \pm 1^{\circ} \mathrm{C}$.

Os tratamentos com tiossulfato de prata e amônia quaternária consistiram na imersão da base das hastes florais nas referidas soluções, por seis e dez horas, respectivamente. Esses períodos de imersão tiveram por base resultados de testes preliminares. Em seguida, as inflorescências foram mantidas em erlenmeyers com água destilada. A troca de água dos frascos e as avaliações foram realizadas a cada dois dias, tendo as avaliações início um dia após a aplicação dos tratamentos.

Para cada inflorescência, foi atribuída uma nota, a cada dois dias, visando avaliar os aspectos qualitativos da inflorescência (cor, turgescência, escurecimento e curvatura das brácteas), de acordo com o critério a seguir. Cor: nota $3=$ cor viva; nota 2 = levemente desbotada; nota $1=$ desbotada; nota $0=$ muito desbotada, descarte. Turgescência: nota $3=$ túrgida; nota 2 = levemente murcha; nota 1 = murcha; nota $0=$ muito murcha, descarte. Escurecimento das brácteas: nota $3=$ nenhuma bráctea escurecida; nota $2=5$ a $19 \%$ das brácteas escurecidas; nota $1=20$ a $29 \%$ das brácteas escurecidas; nota $0=30 \%$ ou valor acima de brácteas escurecidas, descarte. Curvatura da inflorescência em relação à haste: nota 3 = inflorescência reta; nota 2 = inflorescência formando ângulo $\leq 30^{\circ}$; nota $1=$ inflorescência formando ângulo entre 31 e $90^{\circ}$; nota $0=$ inflorescência formando ângulo $>90^{\circ}$, descarte. A vida de vaso foi considerada encerrada quando $30 \%$ ou mais das brácteas de uma inflorescência apresentaram-se sem atrativos. 
Foram também realizadas avaliações de coloração através de colorímetro Minolta CR 200b, que utiliza o sistema da CIE 1976 (MINOLTA CORP., 1994), o que permitiu calcular a luminosidade $(L)$, o ângulo Hue ou de cor $\left(h^{\circ}\right)$ e a cromaticidade $(C)$ das inflorescências. Marcou-se uma bráctea na posição mediana de cada inflorescência e procedeu-se à leitura na bráctea subseqüente, obtendo-se desse modo a padronização das medições.

A evolução de $\mathrm{CO}_{2}$ foi determinada a cada dois dias, sendo que cada repetição, contendo três inflorescências em solução de manutenção, foi colocada em um recipiente plástico, hermeticamente fechado, com capacidade para 15 litros, por uma hora, em ambiente de laboratório. Foram tomadas alíquotas de $0,3 \mathrm{~mL}$ do conteúdo da atmosfera do interior dos recipientes, antes e imediatamente após esse período, tendo seus teores de $\mathrm{CO}_{2}$ determinados em cromatógrafo (GC Finnigan 9001) equipado com detectores de condutividade térmica e de ionização de chama, assim como peneira molecular, metanador e coluna de aço inoxidável preenchida com Porapak N. As condições de trabalho foram: temperatura da coluna $=55^{\circ} \mathrm{C}$, temperatura dos detectores $=150{ }^{\circ} \mathrm{C}$, temperatura do metanador $=350^{\circ} \mathrm{C}$; fluxo de ar $=175 \mathrm{~mL} \cdot \mathrm{min}^{-1}$; fluxo de hidrogênio $=15 \mathrm{~mL}$. $\mathrm{min}^{-1}$; e fluxo do nitrogênio $=30 \mathrm{~mL} \cdot \mathrm{min}^{-1}$. Os resultados para $\mathrm{O}_{2}$ e $\mathrm{CO}_{2}$ foram expressos em porcentagem, tendo como padrão uma mistura gasosa contendo $\mathrm{O}_{2}(10 \%), \mathrm{CO}_{2}$ $(0,11 \%)$, etileno (51 ppm) e $\mathrm{N}_{2}$ para completar $100 \%$.

Os dados obtidos foram submetidos à análise de variância por meio do teste $\mathrm{F}$.

\section{RESULTADOS E DISCUSSÃO}

Verificam-se na Tabela 1 os resultados da análise de variância para as características avaliadas em inflorescências de Alpinia purpurata, submetidas aos diferentes tratamentos. Na mesma tabela, nota-se que houve interação entre tratamentos e dias de avaliação. $\mathrm{O}$ alto valor do coeficiente de variação encontrado para massa fresca ocorreu, provavelmente, devido à grande variação entre as massas frescas iniciais das inflorescências das alpínias, apesar do cuidado na padronização e casualização das hastes florais nos diferentes tratamentos.

$\mathrm{Na}$ Figura 1, pode-se observar que houve manutenção da curvatura e turgescência, até o sexto dia de vida no vaso, para todos os tratamentos, com exceção do tiossulfato de prata (STS). O tratamento com STS mostrou-se fitotóxico às inflorescências de alpínia, causando perda na qualidade logo nos dois primeiros dias de vida no vaso (Figuras 1 e 2). Segundo REID (1989), a solução de "pulsing" contendo $2 \mathrm{mM}$ de tiossulfato de prata (STS), por quatro horas, causou fitotoxidade e reduziu em um terço a vida de vaso de inflorescências de alpínia. Esses resultados revelam que, possivelmente, as inflorescências de alpínia devam ser sensíveis ao íon prata, pois de acordo com CAMERON \& REID (1981), além da formulação, a concentração a ser utilizada e a fitotoxidade provocada pelo íon prata variam para cada espécie.

Observou-se uma redução significativa da turgescência e maior curvatura das hastes a partir do sexto dia, com maior intensidade no tratamento com água destilada (controle) e tiossulfato de prata. Resultado semelhante pode ser verificado pelas notas para coloração e escurecimento das inflorescências (Figura 2). O escurecimento pode estar relacionado com o estresse hídrico (DE SWARDT, 1977; PAULL et al., 1981), ou ao baixo nível de carboidratos segundo REID (2002).

Tabela 1. Resultados da análise de variância obtidos para as características, cor, turgescência, curvatura e escurecimento, avaliadas em inflorescências cortadas de Alpinia purpurata, submetidas a diferentes tratamentos

\begin{tabular}{|l|c|c|c|c|c|}
\hline Causas de variação & G.L & Cor & Turgescência & Curvatura & Escurecimento \\
\hline Soluções (S) & 4 & $51,2024^{* *}$ & $58,1274^{* *}$ & $45,1190^{* *}$ & $65,1155^{* *}$ \\
\hline Dias (D) & 6 & $42,7167^{* *}$ & $30,1833^{* *}$ & $10,7103^{* *}$ & $26,3429^{* *}$ \\
\hline Interação SxD & 24 & $4,4677^{* *}$ & $5,1149^{* *}$ & $5,7163^{* *}$ & $4,7585^{* *}$ \\
\hline Resíduo & 105 & 0,0877 & 0,1216 & 0,0353 & 0,1030 \\
\hline C.V. (\%) & & 14,21 & 15,85 & 7,34 & 14,56 \\
\hline
\end{tabular}

** - significativo $(\mathrm{P}<0,01)$. 

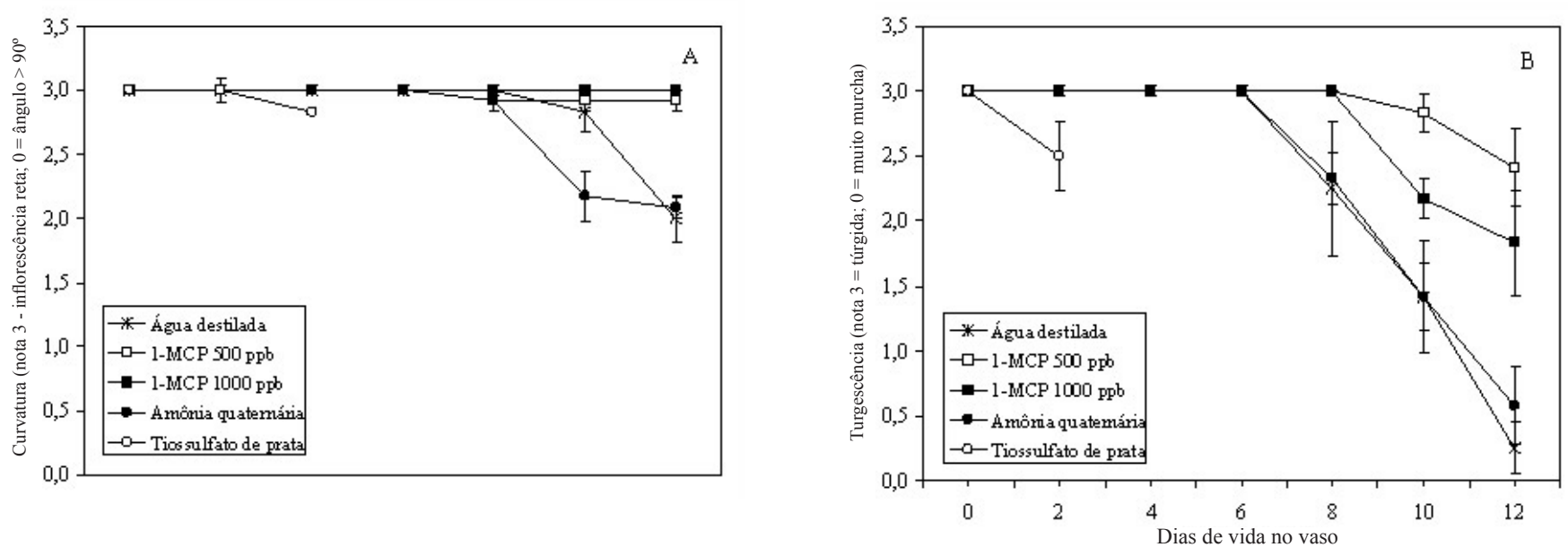

Figura 1. Evolução das características qualitativas, curvatura (A) e turgescência (B), em inflorescências de Alpinia purpurata, durante os dias de vida no vaso.
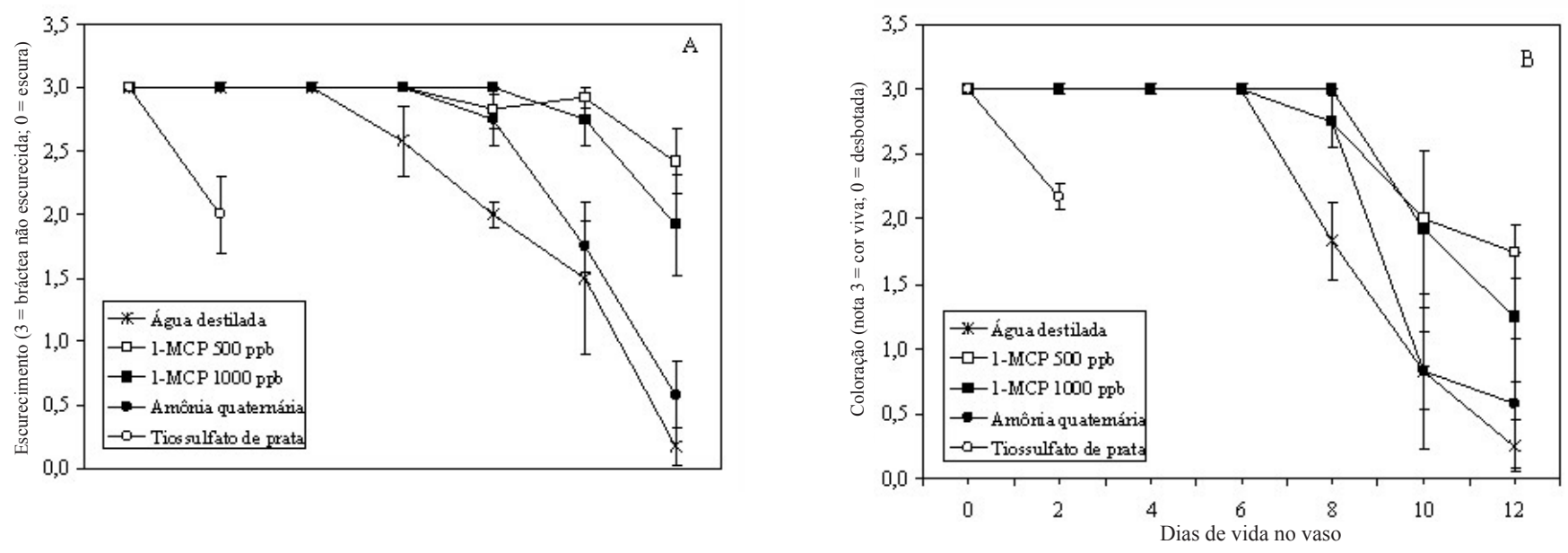

Figura 2. Evolução das características qualitativas, escurecimento (A) e coloração (B), em inflorescências de Alpinia purpurata, durante os dias de vida no vaso.

Houve interação significativa entre as soluções e os dias de avaliação, para a perda acumulada de massa fresca das inflorescências de Alpinia purpurata. $\mathrm{Na}$ Figura 3, é possível verificar que aos doze dias houve perda acumulada de $37,14 \%$ para as inflorescências mantidas em água destilada, diferindo estatisticamente dos demais tratamentos. Resultados semelhantes também foram obtidos por PAULL (1991) em inflorescências de alpínia, sendo o murchamento e o escurecimento das brácteas atribuídos ao bloqueio vascular nos tecidos e à redução das substâncias de reserva. O tratamento das inflorescências com o inibidor de etileno 1-MCP a $500 \mathrm{ppb}$ proporcionou a menor perda de massa fresca $(11,46 \%)$ pelas inflorescências de Alpinia purpurata.

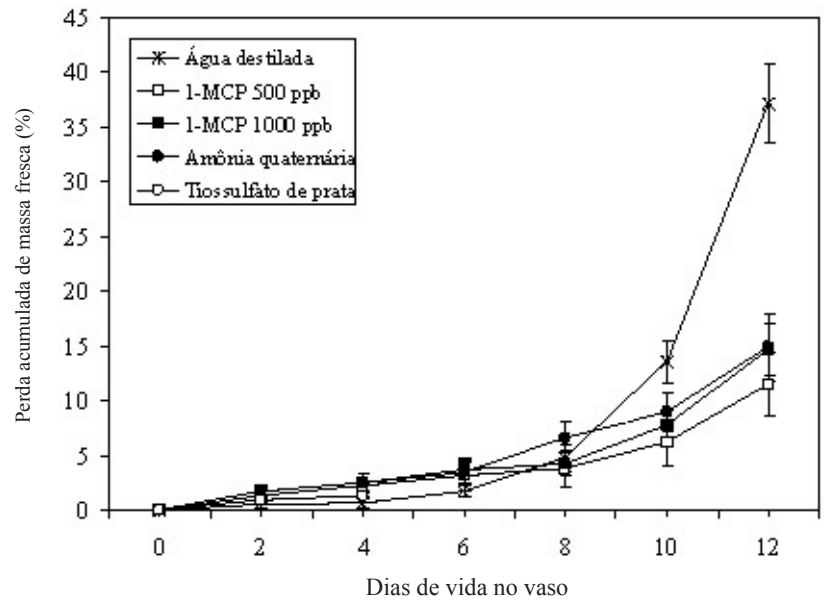

Figura 3. Perda acumulada de massa fresca das inflorescências de Alpinia purpurata, submetidas a cinco tratamentos, após a colheita. 
A análise de variância dos dados de coloração (luminosidade, ângulo Hue e cromaticidade) demonstra haver interação dos tratamentos com os dias de vida de vaso somente para a cromaticidade (Tabela 2). Para as características luminosidade e ângulo Hue houve diferenças significativas somente para os efeitos principais. A maior redução na luminosidade, que é representada por uma escala de zero (preto) a cem (branco), pode ser verificada nas inflorescências que estavam na água destilada (Figura 4). Para os demais tratamentos, com exceção do STS, houve manutenção desses valores durante os dias de vaso, com destaque para as inflorescências tratadas com 1-MCP a 500 ppb (Figura 4).

Apesar de não terem ocorrido diferenças significativas para a interação dos fatores, verifica-se que as inflorescências tratadas com o 1-MCP a $500 \mathrm{ppb}$ apresentaram a melhor manutenção da cor vermelha, expressa pelo ângulo de cor, em relação aos demais tratamentos (Figura 5). De acordo com SKOG et al. (2001), tratamentos com 1-MCP a $0,5 \mathrm{ppb}$, por seis horas, em espécies florais como rosas, esporinha, bocade-leão, gipsofila, alstroemeria, lírios e poinsetias, resultaram em qualidade superior das flores tratadas em relação às plantas controle, o que demonstra que o 1-MCP pode bloquear a ação do etileno (RUPASINGUE et al., 2000).

Com relação à cromaticidade, nota-se que houve redução na intensidade da cor a partir do oitavo dia de avaliação em todos os tratamentos e que a manutenção dessa intensidade foi melhor nas inflorescências tratadas com 1-MCP (Figura 6), com destaque para o tratamento $1-\mathrm{MCP}$ a $500 \mathrm{ppb}$ que diferiu estatisticamente dos demais tratamentos.

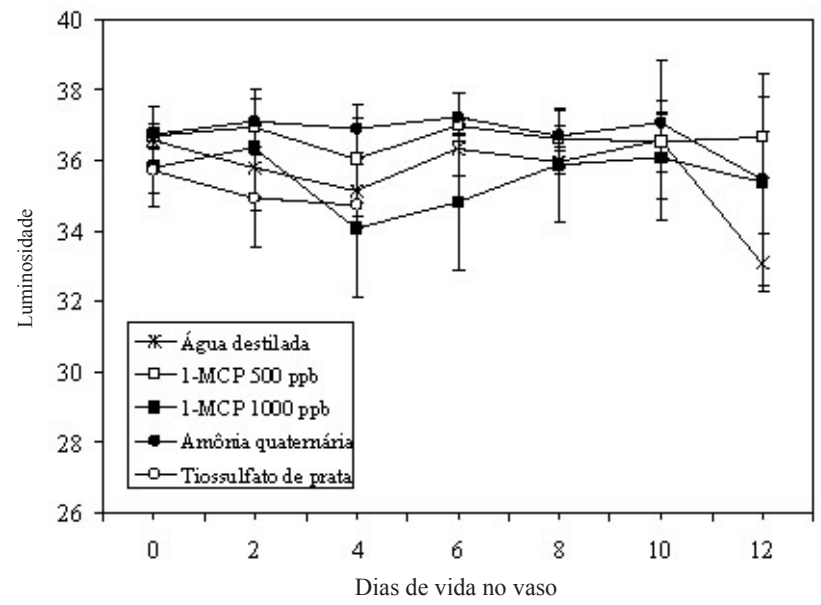

Figura 4. Valores da luminosidade da superfície externa das brácteas das inflorescências de Alpinia purpurata, submetidas a diferentes tratamentos de pós-colheita.

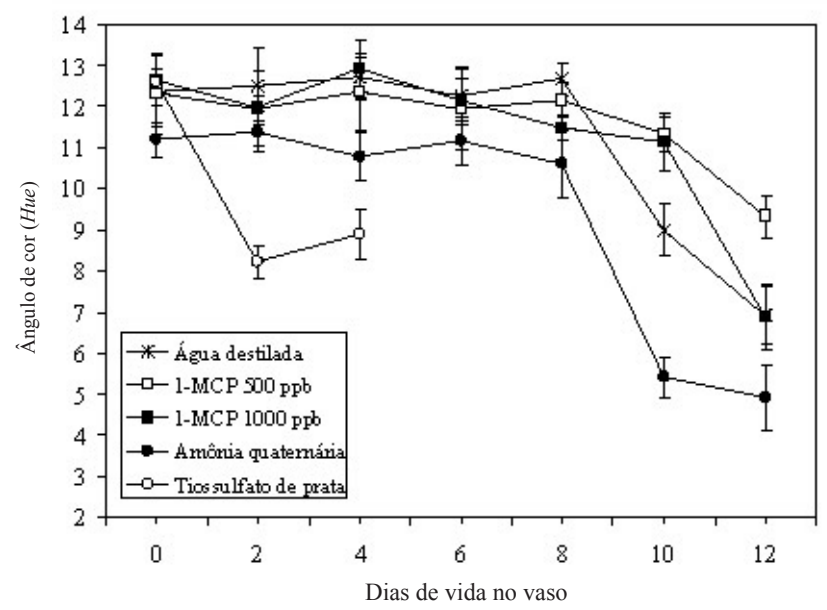

Figura 5. Valores do ângulo Hue da superfície externa das brácteas das inflorescências de Alpinia purpurata, submetidas a diferentes tratamentos de pós-colheita.

Tabela 2. Resultados da análise de variância obtidos para as características, massa fresca, luminosidade, ângulo hue e cromaticidade, avaliadas em inflorescências cortadas de Alpinia purpurata, submetidas a diferentes tratamentos

\begin{tabular}{|l|c|c|c|c|c|}
\hline Causas de variação & G.L & Massa fresca & Luminosidade & Ângulo hue & Cromaticidade \\
\hline Soluções (S) & 4 & $222,6731^{* *}$ & $27,2832^{* *}$ & $41,7411^{* *}$ & $170,7383^{* *}$ \\
\hline Dias (D) & 6 & $2912,7282^{* *}$ & $11,0182^{*}$ & $112,9202 * *$ & $450,6584 * *$ \\
\hline Interação SxD & 24 & $198,9380^{* *}$ & $4,0772^{\text {n.s. }}$ & $10,2370^{\text {n.s. }}$ & $63,8873^{* *}$ \\
\hline Resíduo & 105 & 15,9890 & 4,5166 & 6,6913 & 9,2571 \\
\hline C.V. $(\%)$ & & 71,5448 & 5,88 & 23,59 & 7,07 \\
\hline
\end{tabular}

n.s. não significativo $(\mathrm{P}>0,05)$; ** significativo $(\mathrm{P}<0,01)$. 


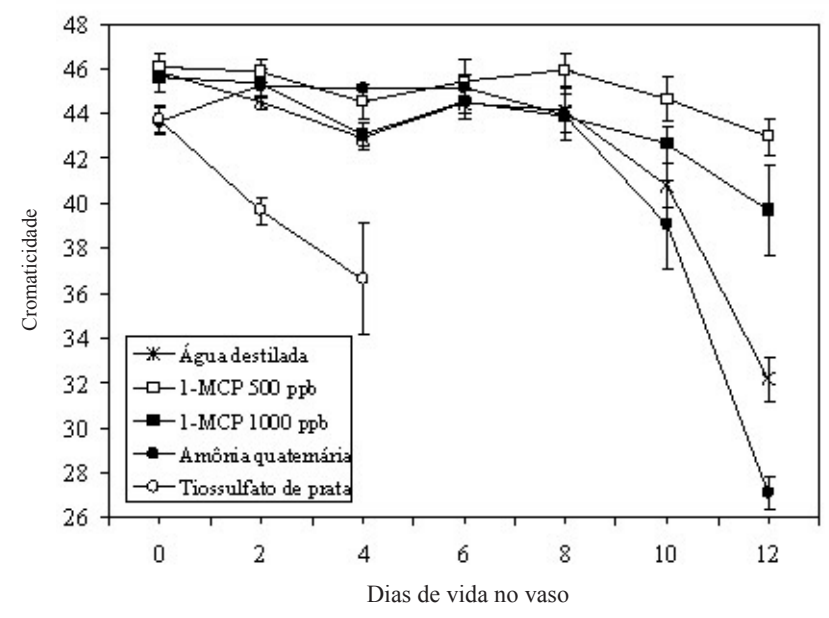

Figura 6. Valores de cromaticidade da superfície externa das brácteas das inflorescências de Alpinia purpurata, submetidas a diferentes tratamentos de pós-colheita.

A estabilidade dos parâmetros de coloração demonstrou que o tratamento com o inibidor de etileno 1-MCP possibilitou a manutenção da qualidade das inflorescências de Alpinia purpurata. A eficiência do 1-MCP também foi relatada em experimentos realizados com outras espécies ornamentais como Alstroemeria, Anthirrinum, Consolida, Dianthus caryophyllus, Petunia (SEREK et al., 1995), Begonia, Campanula carpatica, Kalanchoe, Rosa (SEREK et al., 1994b; SISLER \& SEREK, 1999), Phalaenopsis (PORAT et al, 1995) e Lupinus havardii (SANKHLA et al., 2001).

As inflorescências de Alpinia purpurata tratadas nas soluções com tiossulfato de prata (na primeira avaliação) e amônia quaternária, principalmente aos quatro, oito e dez dias de vida no vaso, apresentaram as maiores taxas respiratórias quando comparadas com os demais tratamentos (Figura 7). O tratamento com STS apresentou, inicialmente, uma elevada taxa respiratória, que se reduziu pela metade, em dois dias, o que culminou com o descarte das inflorescências. Em cravos mantidos a $20^{\circ} \mathrm{C}$, a taxa respiratória foi de $239,0 \mathrm{mg} \mathrm{CO}{ }_{2} \cdot \mathrm{h}^{-1} \cdot \mathrm{kg}^{-1}$ (MAXIE et al., 1973) e em rosas cortadas essa taxa $\left(22,2^{\circ} \mathrm{C}\right)$ foi de $600 \mathrm{mg} \mathrm{CO} \cdot \mathrm{h}^{-1} \cdot \mathrm{kg}^{-1}$ no dia da colheita e próxima de $300 \mathrm{mg} \mathrm{CO} \cdot \mathrm{C}^{-1} \cdot \mathrm{kg}^{-1}$ após dois, três e quatro dias (COORTS, 1973). O tratamento com amônia quaternária estimulou a respiração ao longo dos dias de vida no vaso, até o décimo dia de avaliação, quando as inflorescências não mais apresentavam qualidade comercial. Resultados semelhantes foram verificados em flores de Gypsophila paniculata, em solução de "pulsing", quando os ingredientes amô- nia quaternária, tiossulfato de prata e sacarose também não aumentaram a vida de vaso e não foram eficientes em reduzir os sintomas de senescência (BARRERA \& ARENAS, 2001).

As inflorescências submetidas ao tratamento com 1-MCPapresentaram a melhor qualidade após doze dias de vida no vaso (Figura 8). Esse tratamento possibilitou taxas respiratórias menores (Figura 7), indicando uma menor utilização das reservas como substrato respiratório, o que permitiu a manutenção da qualidade das inflorescências. Para manterem-se vivas, as flores necessitam de substrato para a utilização no processo bioquímico da respiração, que gera energia vital a elas.

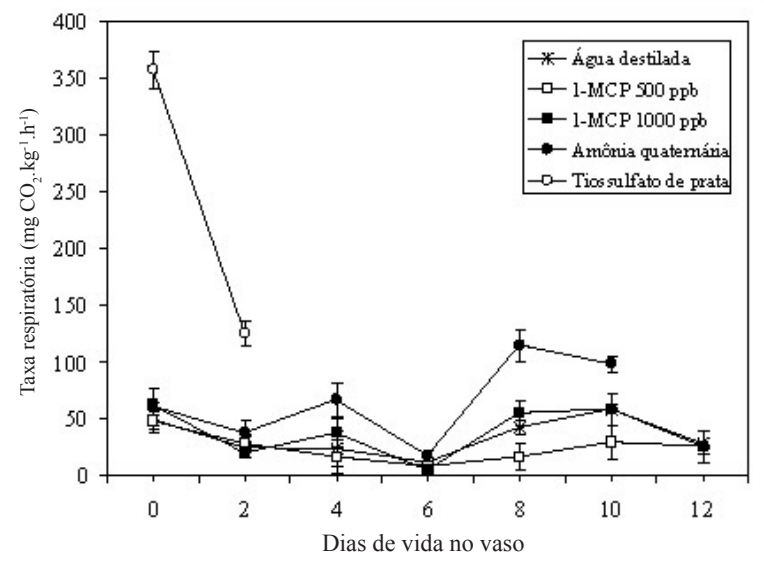

Figura 7. Atividade respiratória de inflorescências de $\mathrm{Al}$ pinia purpurata, submetidas a diferentes tratamentos de pós-colheita, a $22{ }^{\circ} \mathrm{C}$ e $67 \%$ UR.

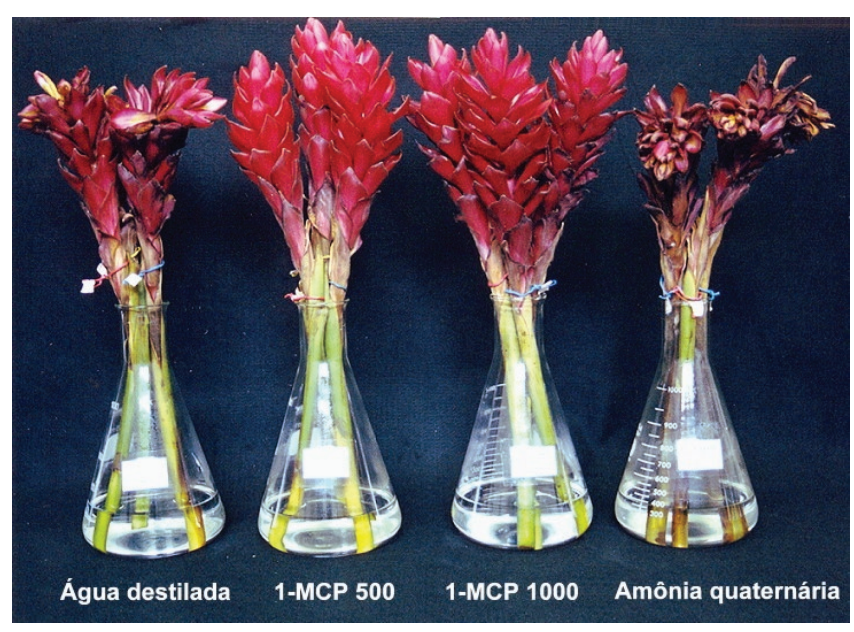

Figura 8. Qualidade final das inflorescências de Alpinia purpurata, submetidas a diferentes tratamentos de pós-colheita, após 12 dias de vida no vaso. 
Esses dados estão de acordo com os de perda acumulada de massa fresca (Figura 3); o tratamento com o 1-MCP também induziu a uma menor perda de água, retardando o murchamento, o esgotamento das reservas orgânicas e a senescência das flores.

\section{CONCLUSÕES}

O tratamento com o inibidor de etileno 1-MCP possibilitou a menor perda de massa fresca e a manutenção da coloração das inflorescências de Alpinia purpurata durante o período de vida no vaso.

As inflorescências foram muito sensíveis ao tiossulfato de prata a $1 \mathrm{mM}$ e perderam a qualidade em dois dias de vida no vaso, em função da elevada perda de água e das altas taxas respiratórias.

As taxas respiratórias das inflorescências, submetidas aos diferentes compostos químicos (exceto ao STS), variaram entre 5,06 e 114,40 $\mathrm{mg} \mathrm{CO}_{2} \mathrm{~h}^{-1} \mathrm{~kg}^{-1}$, sendo esse último valor constatado no tratamento com amônia quaternária aos oito dias de vida no vaso.

\section{REFERÊNCIAS BIBLIOGRÁFICAS}

AKAMINE, E.K; GOO, T. \& SUEHISA, R. Relationship between leaf darkening and chemical composition of leaves of species of Protea. Florist's Review, v.163, p.62-63, 1979.

BARRERA, de A.C. \& ARENAS, G. Cutting-time effect during harvest cycle on postharvest behavior of three Gypsophila paniculata cv. Perfecta clones. Acta Horticulturae, v. 482, p.71-75, 2001.

BOROCHOV, A.; MAYAK, S. \& HALEVY, A.H. Combined effects of abscisic acid and sucrose on growth and senescence of rose flowers. Physiologia Plantarum, v. 36, p. 221-224, 1976.

BURG, S.P. The physiology of ethylene formation. Annual Review in Plant Physiology, v.13, p.265-302, 1962.

CAMERON, A.C. \& REID, M.S. The use of silver thiosulfate anionic complex as a foliar spray to prevent flower abscission of zygocactus. HortScience, Alexandria, v. 16, p. 761-762, 1981

CAMERON, A.C. \& REID, M.S. Use of silver thiosulfate to prevent flower abscission from potted plants. Scientia Horticultural, v.19, p.373-378, 1983.

COORTS, G.D. Internal metabolic changes in cut flowers. HortScience, Alexandria, v.8, n.3, p.195-198, 1973.
CRILEY, R.A. \& PAULL, R.E. Postharvest handling of bold tropical cut flowers: Anthurium, Alpinia purpurata, Heliconia, and Strelitizia. Acta Horticulturae, v.337, p.201-211, 1993.

DAHLGREN, R. M. T.; CLIFFORD, H.T. \& YEO, P.F. The Families of the Monocotyledons-Structure, Evolution, and Taxonomy. New York: Springer- Verlag, 1985.

DE SWARDT, G.E. Metodes om verbruing van proteablare te keer. Landbauweekblad, v.30, p.30-33, 1977.

FARNHAN, D.S.; KOFRANEK A.M. \& KUBOTA, J. Bud opening of Gypsophila paniculata L.cv. Perfecta with Physan-20. Journal of the American Society for Horticulturae Science, Alexandria, v.103, p.382-384, 1978.

HALEVY, A.H. Pollination induced corolla senescence. Acta Horticulturae, v.148, p.123-132, 1985.

HALEVY, A.H. \& MAYAK, S. Improved of cut flower quality opening and longevity by pre-shipment treatments. Acta Horticulturae, The Hague, The Netherlands, n. 43, p. 335-347, 1974.

HALEVY, A.H. \& MAYAK, S. Senescence and postharvest physiology of cut flowers. Horticultural Reviews, Westport, v. 1,n.2, p. 59-143, 1981.

KEPLER, A.K. \& MAU, J.R. Exotic tropicals of Hawaii: heliconias, gingers, anthuriums and decorative foliage. 15. ed. Hawaii: Mutual Publishing, 1996. p.47-48.

LEVY, M. \& HANAN, J.J. Some effects of floral preservatives on carnation keeping life. Colorado Flowers Growers Association, n.341, p.2-4, 1978. (Bulletin)

MAXIE, E.C. et al. Temperature and ethylene effects on cut flowers carnation (Dianthus caryophyllus L.). Journal of the American Society for Horticultural Science, v.98, n.6, p.568-572, 1973.

MAYAK, S. \& HALEVY, A.H. Flower senescence. In: Senescence in plants. THIMANN , K.V. (ed.). CRC Series in Ageing. Boca Raton: CRC Press, 1980. p. 131-156.

MINOLTA CORP. Precise color communication: color control from feeling to instrumentation. Ramsey: Minolta Corporation Instrument Systems Division, 1994, 49p.

NADEAU et al. Temporal and spatial regulation of 1aminocyclopropane-1-carboxylic acid oxidase in the pollination induced senescence of orchid flowers. Plant Physiology, n.103, p.31-39, 1993. 
PAULL, R. E. Postharvest handling of Hawaii cut flowers for export. In: THE FIRST HAWAII TROPICAL CUT FLOWER INDUSTRY CONFERENCE, 24, Hawaii, 1991. Proceedings... Hawaii: University of Hawaii. 1991.

PAULL, R.E. et al. Leaf blackening in cut Protea eximia: importance of water relations. Acta Horticulturae, v.113, p.71-76, 1981.

PORAT, R.; HALEVY, A.H. \& SEREK, M. An increase in ethylene sensitivity following pollination is the initial event triggering in increase in ethylene production and enhanced senescence of Phalaenopsis orchid flowers. Physiologia Plantarum, v.88, p.243-250, 1995.

REID, M.S. The role of ethylene in flower senescence. Acta Horticulturae, n.261, p.157-169, 1989.

REID, M.S. Postharvest Handling Systems: Ornamental crops. In: KADER, A.A. (ed.) Postharvest technology of horticultural crops. 3. ed. Davis: University of California, 2002. p.315-326.

RUPASINGUE, H.P.V.; MURR, D.P. \& PALIYATH, G. Inhibitory effect of 1-MCP on ripening and superficial scald development in 'McIntosh' and 'Delicious' apples. Journal of Horticultural Science and Biotechnology, v.75, n.3, p.271-276, 2000.

SANKHLA, N.; DAVIS, T.D. \& MACKAY, W.A. Extension of vase life and prevention of ethylene-induced flower shattering in shattering in Lupinus havaardii 1-methylciclopropene. Acta Horticulturae, n. 543, p. 75-78, 2001.
SEREK M.; SISLER, E.C. \& REID, M.S. A volatile ethylene inhibitor improves the post harvest life of potted roses. Journal of the American Society for Horticultural Science, v.119, p.572-577, 1994b.

SEREK, M., SISLER, E.C. \& REID, M.S. Novel gaseous ethylene binding inhibitor prevents ethylene effects in potted flowering plants. Journal of the American Society Horticultural for Science, v.119, p.1230-1233, 1994c.

SEREK, M.; SISLER, E.C. \& REID, M.S. 1methylcyclopropene, a novel gaseous inhibitor of ethylene action, improves the life of fruit, cut flowers and potted plants. Acta Horticulturae, n.394, p. 337$345,1995$.

SISLER, E.C. \& SEREK, M. Inhibitors of ethylene responses in plants at the receptors level: recent developments. Physiologia Plantarum, v.100, p. 577-582,1999.

SKOG, L.J. et al. A survey of ethylene contamination in Ontarios' floriculture industry and the evaluation of 1methylcyclopropene and an ethylene absorber as potential solutions. Acta Horticulturae, n. 543, p. 55-59, 2001.

WANG, H. \& WOODSON, W.R. Reversible inhibition of ethylene action and interruption of petal senescence in carnation flowers by norbornadiene. Plant Physiology, v.89, p.434-438, 1989.

WOODSON, W.R. et al. Expression of ethylene biosynthetic pathway transcripts in senescing carnation flowers. Plant Physiology, v.99, p.526-532, 1992. 